Research Article

\title{
GENDER INEQUALITY AND MORAL VALUES IN "WONDER WOMAN" BY PATTY JENKINS
}

\author{
Ayu Yuliani Eddy 1 \\ Postgraduate Faculty,_English Education Program \\ Universitas Indraprasta PGRI \\ email: yuyaayu44@gmail.com ${ }^{1}$
}

\begin{abstract}
The title of this thesis is "Gender Inequality and Moral Value in "Wonder Woman" by Patty Jenkins." The study was conducted in August 2019. This research paper's objective was to find out the gender inequality and moral value of this movie. The research method was qualitative. The instruments of this research have covered the list of questions designed based on the elements of the movie. The data was collected by watching the movie and reading the script movie, identifying, classifying, and analyzing gender inequality and moral value. 1). The result of this research showed the Gender Inequality has the highest percentage of Gender Equality. The draw of Gender conclusion is that Gender Inequality is $33,45 \%$ and Gender Equality is $21,00 \%$. 2). The moral values are justice $17,41 \%$, honesty $33,45 \%$, bravery $17,10 \%$, responsibility $30,89 \%$, and beneficence $31,11 \%$. The valuable input of analyzing the movie is that the movie can be used as advice for teacher of English to make students have a positive character.
\end{abstract}

Keywords: gender inequality; moral value; movie

\section{Introduction}

Literature is the only part of the educational curriculum that deals directly with the actual world of lived experience. We should read literature and study it and take it seriously because it enriches us as human beings. Literature does not just take up space, and it orients readers or viewers in new directions. It enriches their schemas for interpreting the fictional social worlds they enter temporally and the actual everyday social worlds in which they live. Occasionally, the work of literature, for example, is the movie "change our lives, motivating viewers to the kinds of concrete actions that bring profound change in their life possibilities. Using movies and multimedia in language teaching allows second or foreign language learners to acquire more genuine and useful learning materials. It also helps students understand the target people and culture as well as learn the target language. Of course, each of the movies has a moral message that can we take the benefit such as in "Wonder Woman" (Jenkins, 2017) the movie. A moral message is a message conveyed or a lesson to be learned from a story or event. By representing the interconnected lives of different characters that are all negotiating multiple and overlapping structures of power and privilege, a good work of literature can suggest to its readers how race, ethnicity, gender, and sexuality constrain and enable characters, bodies, behavior, and ideologies. In this way, some works of literature allow a reader and viewer to perceive (or a literary critic to analyze) the way race, ethnicity, gender, and sexuality matterboth in the sense of being critical and meaningful and in the sense of becoming materialized in individual lives. Likewise, gender inequality is also often exposed to literary works and moral values that always appear in the literature. For the viewer or audience, a moral value is also vital in choosing the movie that they watch because a moral message in the movie can influence the attitude of the people.

Gender is not a matter of gender, while gender is merely talking about biology. Women have a uterus, breasts, can give birth, breastfeed, conceive, while men do not. Men have sperm to fertilize an egg; men have a particular hormone, which is different from female hormones to perform their biological functions. But the biological functions of men and women are then mixed up in their social and political life. Whereas the biological determinations of men and women are solely reproductive devices of their bodies, which also occur in various other species of creatures, which should not have any assessment 
intervention or any social outlook beyond its function. Gender is not gender, but the biological existence of human beings. Gender is beyond human biological factors, and the term gender actually wants to explain that there are problems in these two sexes in their social political life. There are problems in the relations of men and women in facing their social and political conditions. The issue is not from those who are born in a situation (sex) male or female, but because of the social and political perspective of the community towards them. Gender is a socially constructed definition of women and men. It is not the same as sex (biological characteristics of women and men) and it is not the same as women. Gender is determined by the conception of tasks, functions and roles attributed to women and men in society and in public and private life.

Thomas and Tylman (2004) stated, "The word 'gender' is a word without demands, without political clout and is considered to mean women. It therefore has little to do with the real business of life, politics, war or profit". Understandings of gender continually evolve. In the course of a person's life, the interests, activities, clothing and professions that are considered the domain of one gender or another evolve in ways both small and large. Gender tends to denote the social and cultural role of each sex within a given society. Rather than being purely assigned by genetics, as sex differences generally are, people often develop their gender roles in response to their environment, including family interactions, the media, peers, and education. Gender refers to the socially constructed characteristics of women and men, such as norms, roles, and relationships of and between groups of women and men. It varies from society to society and can be changed. Bravo-Baumann (2000) stated "gender roles are the 'social definition' of women and men. They vary among different societies and cultures, classes, ages and during different periods in history.". Gender is indeed not rooted in Indonesian, and gender is not just one word with one understanding. Gender is a concept that tells many things about the lives of two human sexes, namely men and women. The term gender departs from our awareness that humans are not one, humans vary, in this case is their gender. Gender refers to a culture that treats humans - men and women differently, whereas in humanitarian principles, they are two types of people who have equal human rights. Gender refers to a view of the social culture of society, which distinguishes the lives of women and men, makes life experiences differentiated. Gender is a term that wants to explain that there are factors outside of human existence that affect the lives of men and women.

Meanwhile, Pilcher \& Whelehan (2004), "The concept of gender, as we now use it came into common parlance during the early 1970s. It was used as an analytical category to draw a line of demarcation between biological sex differences and the way these are used to inform behaviors and competencies, which are then assigned as either 'masculine' or 'feminine'. The purpose of affirming a sex/gender distinction was to argue that the actual physical or mental effects of biological difference had been exaggerated to maintain a patriarchal system of power and to create a consciousness among women that they were naturally better suited to 'domestic' roles". The term gender wants to explain that culture has made the relationship between two sexes, men, and women, experience a gap with such a deep gap. They "do not connect" in communication, they are awakened by mental and opposite ways of thinking. They stand on their respective cultures. Women's culture is very different from male culture. Their values are split into two. They are called masculine and feminine. They may not exchange roles, whereas the human nature is so beautiful, both have thoughts, hearts, and souls, which should be actualized in their daily lives. They are imprisoned by roles for their gender reasons, and this is a function of the concept of gender, and in its development, gender becomes a study that can be learned through various scientific disciplines such as philosophy, anthropology, sociology, politics, law, art and culture, as well as science and technology.

Women are not expected to be smart, work, career and succeed in certain fields, they are only expected to manage the household, take care of children. While men are placed opposite women, they must be successful at work, must be smart, must have a high career, must be rich. There is nothing more worthless than a poor man who is unable to support his family, rather than a woman who is poor but can be supported by her husband. Or in certain traditions and religions, a wife is allowed to be beaten by her husband, if he does not have permission to leave the house. Beating to wives is an act that is considered very reasonable in this matter. The term gender is a knife that unfolds the bitter reality of social and cultural constructions that are believed and believed to be truth or human destiny. It only makes these two human sexes continue to be afflicted with problems, without knowing how to solve them. This is what is called gender inequality.

Why are there gender inequalities between men and women? Nowadays there are many women who are educated and working, it looks like women have advanced, but do you know in the whole world 
the average woman only gets $70 \%$ of the average salary of men $100 \%$. And now there are also many women who work in government, parliament, and companies, to political parties. but almost all of them do not sit in decision-making positions, so is this fact that gender equality has been realized between women and men? The answer is not yet. Then why is there still equality? Gender equality cannot be realized only by opening opportunities for women, it involves the perspective and mindset. The term gender itself is created to distinguish it from gender biologically. Gender refers to physiological and biological criteria such as genitals, hormones, and chromosomes.

Jayachandran (2015) stated, "gender inequality is Gender gaps favoring males - in education, health, personal autonomy, and more-are systematically larger in poor countries than in rich countries." Gender inequality is also caused by the presence of gender bias based on the knowledge of the people who tend to be gender inequitable. Existing socio-cultural culture places women in the second class, women are more dominated by men. The culture of patriarchal hegemony places men as leaders in family, organization, and politics, so that women's participation in decision making is still relatively low. The lack of opportunities women has to take part in decision making or even become leaders of an organization makes women prefer to be passive. Moral is knowledge that involves the character of civilized humans. Moral also means good and bad teachings of actions and behavior (morals). Moralization means a description (views, teachings) of good deeds and behavior. Moral understanding is distinguished by the notion of prevalence, although in the practice of daily life the two definitions are not clearly defined. The prevalence is good habits without long thoughts are considered good, decent, polite, manners, etc. Thus, morals are norms that are followed without thinking long are considered good, which are based on habits or traditions.

Hurlock (1997) stated, "moral is a habit, procedure, and custom of a rule of behavior that has become a habit for members of a culture in society". Moral not only an impact on individuals, but it is also very possible to have an impact on others. Good or bad moral, depends on conscience and character possessed by each individual. Because everyone has a different understanding and application of character, the morals of each person also vary. An assessment of one's good or bad morals will have a direct impact on a group or organization, and society. An example is when someone is said to be immoral, he will do bad things that can harm the community such as harassment, murder, theft, disrespect for older people, and so forth. Back again who will judge an action as moral or not is another person or community. So that moral is an action and interaction that is carried out by someone where the action will be assessed whether it is acceptable or not with the norms and culture that apply in society. An understanding of morality distorted from legality is found in Kant's moral philosophy. In his opinion, morality is the suitability of attitudes and actions with inner norms or laws, namely what Kant sees as "obligation". Whereas legality is the suitability of attitudes and actions with mere outer law or norms.

This conformity has not been of moral value, because it is not based on inner encouragement. Morality will be achieved if in obeying outer law not because of fear of the consequences of the outward law, but because of realizing that obeying the law is an obligation. Thus, new moral values will be found in morality. That inner impulse cannot be captured with the senses, so that it is impossible for people to judge giving absolute moral judgment. Kant firmly stated, "Only God knows that one's inner impulses are moral" (as cited in Tjahjadi, 1991, p. 48). In the view of philosophy, the value is usually associated with the problem of goodness. something is valued if something is useful, valuable and useful. value is something important and useful, or the more useful an object is, the higher the value of the object. Likewise, it is as low as the usefulness of an object, so it may be of lower value for the object. Clutterbuck (2007) stated, "values are those behavioral traits, attitudes and concepts that have created the type of person you are. Your character is perceived in the minds of others by the presence or absence of these values within you. Are you caring, honest and reliable, possessing the numerous values that complement each other? Or are you perceived as someone unkind and not to be trusted? Some of our innate values will be stronger and more obvious than others. A person who is scrupulously honest may not have the same strengths in assertiveness or tolerance. Sometimes it takes a great deal of concentration and hard work to develop internal behaviors that will produce positive concepts of you in the minds of others."

Based on the above meanings, it can be reiterated that the value is a reference and confidence in making choices. In line with that definition, what is meant by the nature and meaning of values is in the form of norms, ethics, regulations, laws, customs, religious rules, and other references that have a price and are felt valuable to someone. Values are abstract, are behind facts, give rise to actions, are contained in one's morality, emerge as the ends of psychological processes, and develop towards more complex. Value 
is something that useful and good that aspired to and considered important by society. Something said to have value, if it has usefulness, truth, goodness, beauty and religiosity. While norms are provisions that contain orders or prohibitions that citizens must obey for the realization of values. Value is something that is considered good or bad for life. Value is something abstract, but it becomes a guideline for people's lives. Norms are guidelines or benchmarks for a person's behavior and actions that are based on values.

Moral is thing that related skill to decide right and wrong of behavior that accepted by citizen. Moral is a regulation that is very important to be enforced in a society because it can be a sign in life and a protector for the community itself. The moral is generated from intellectual, emotional, or intuitive thinking results of each individual which in the end is a rule in life to respect and be able to distinguish between right and wrong that applies in a society. Humans depend on morality, customs, community habits and religion to help assess a person's behavior. Moral value is related to morality. Morality can be interpreted on the one hand as manners, everything related to etiquette or manners. Morality is a guideline that is owned by individuals or groups about what is right and wrong based on moral standards in the community or groups, both small groups of families come to large groups of society. Chaplin \& Robinson (2012) stated, "moral value refers to morals that are in accordance with social rules or concerning laws or customs that govern behavior". Moral value can come from sources of tradition or customs, religion or an ideology or a combination of several sources. Moral standards are standards that are related to problems that are considered to have serious consequences, are based on reasoning that is either not the authority of power, exceeds its own interests, is impartial and the violations are associated with feelings of guilt, shame, regret, and others. Related to the explanation above, the writer found the formulation of the problem in this research needed the following information: (1) How is The Gender inequality in "Wonder Woman" by Patty Jenkins? (2) How is the moral value in "Wonder Woman" by Patty Jenkins?

\section{Method}

In this research the researcher uses qualitative methods conducting the research. In case of qualitative research, the researcher had elaborated what kind of qualitative research that used. Basically, there are many kinds of qualitative research, but based on what had been explained before that the data this research was dealing with the language used in the film, then the researcher decided that this research dealing with qualitative descriptive research. Descriptive research is involving naturalistic data (Creswell, 2009; Endraswara, 2008; Sugiyono, 2009), that is attempting to study language learning and teaching in their naturally occurring settings without any intervention or manipulation of variables. The goal of this research is to describe a phenomenon and its characteristics.

\section{Results and Discussion}

"Wonder Woman" (Jenkins, 2017) is an American superhero film based on the DC Comic's character of the same name. The story about an Amazon princess finds her idyllic life on an island occupied only by female warriors interrupted when a pilot crash-lands nearby. After rescuing him, she learns that World War I is engulfing the planet, and vows to use her superpowers to restore peace. The main character has a good inspiration for people to be brave and more care of people arounds. This film also teaches the audience the justice, honesty, responsibility, and beneficence. After watching the film intensively and focusing on the dialogue the writer would like to present the description and the interpretation of the data in accordance with the Gender Inequality and Moral Value conveyed by the film. There is comparison between Gender inequality and equality of movie presenting in this writing. The writer can draw conclusion that the Gender Inequality found in film "Wonder Woman". Gender Inequality is $33.5 \%$ and Gender Equality is $21,00 \%$ 
Table 1 Percentage in Percent (\%) of Gender Inequality and Equality

\begin{tabular}{|c|l|c|c|}
\hline No & Kinds of Gender & Times of Show up & Percentage \\
\hline 11 & Equality & 8 & $21,00 \%$ \\
\hline 22 & Inequality & 13 & $33,45 \%$ \\
\hline
\end{tabular}
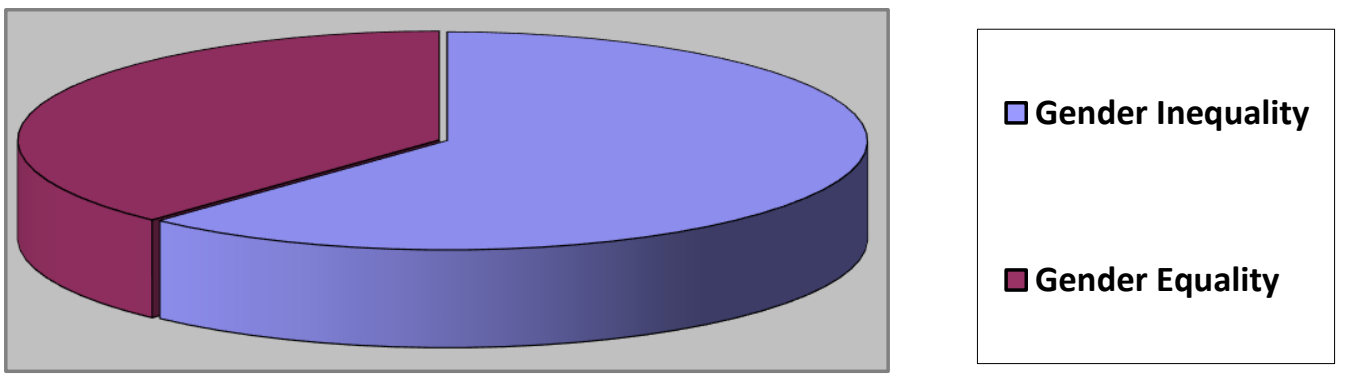

Diagram 1 Gender Inequality and Equality

Moral value in film "Wonder Woman" by Patty Jenkins

Moral values are values that express ideas about the good life. There is constant debate which values constitute the good life. Moral values are abstract and are normative because they say something about the good life, about good and bad. There are five moral values found in wonder woman film, including justice, responsibility, bravery, beneficence, and honesty.

Table 2 Percentage in percent $(\%)$ of Moral Value

\begin{tabular}{|c|l|c|c|}
\hline No & Kinds of Moral Value & Times of Show up & Percentage \\
\hline 11 & Justice & 6 & $17,41 \%$ \\
\hline 22 & Honesty & 13 & $33,45 \%$ \\
\hline 33 & Bravery & 5 & $17.10 \%$ \\
\hline 44 & Responsibility & 9 & $30,89 \%$ \\
\hline 55 & Beneficence & 10 & $31,11 \%$ \\
\hline
\end{tabular}



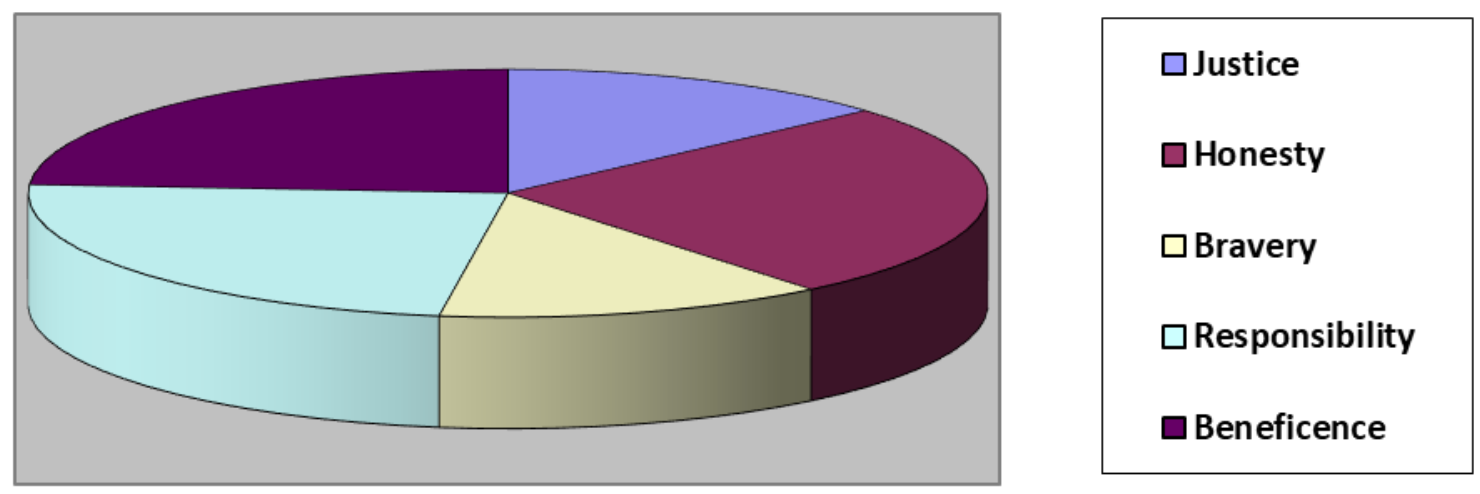

\section{Diagram 2 Kinds of Moral Value in the film}

After analyzing the data found in film "Wonder Woman", the writer can draw conclusion that the Gender Inequality found in film "Wonder Woman". Gender Inequality is $33.45 \%$ and Gender Equality is $21,00 \%$. Based on the result of the data which exist on the film, Gender Inequality gets the highest percentage of the Gender Equality due the fact that film is about a woman who grew up believing in the need to fight, she wanted to fulfill her destiny as an Amazon to defend the world from the chaos and destruction of war. She is a fierce warrior and can't wait to show off her ability to defeat the enemy, but her goal in fighting is only to end the war itself. The more she saw for herself the situation of the victims of the war, the more certain she was of the importance of stopping the war, and this made her even more 'raging' at the same time uncertain and fearful of releasing his true strength. Her mission changed from what was not personally, she was 'just' carrying out what was assigned by God - to be more personal and her sense of truth grew.

The gender equality gets lowest in percentage. It is not surprising since the equality in this film shown by Steve, not only Diana who learned valuable lessons, this film has two characters who study outside the 'comfort' of his world. The first round of the film is about Steve who learned about the world and Diana's motivation. This man was tired of fighting, he wanted to stop the war as soon as possible with no more casualties. The action is now limited to those who might. But the presence of Diana and all her desires, made Steve have a new reason to believe, to take greater risks. He feels more optimistic about humanity, and towards love. Relationship Diana and Steve are very compelling. Chemistry both feels genuine. They both learn from each other. And it's not like, Steve is the weak person who has to be saved. Steve gave a lot to the development of Diana's character, and vice versa.

\section{Moral value in film "Wonder Woman" by Patty Jenkins}

After analyzing the data found in film "Wonder Woman" by Patty Jenkins, the writer can draw a conclusion that the moral value which emerge in film "Wonder Woman", Justice 17,41\%, Honesty 33,45\%, Bravery $17,10 \%$, Responsibility $30,89 \%$ and Beneficence $31,11 \%$. Honesty and Beneficence get the highest percentage due the fact that the film would like to talk much about how to be honest and loving and caring for other. It's about being kind to others and not only thinking about yourself. This film also teaches the audience to never stop learning and to look beyond what can be seen. It is truly hopes that every person watching this film willing to apply it in their life in everyday living.

\section{Conclusions}

After the analysis has been done, the writer concluded that the film entitled "Wonder Woman" by Patty Jenkins, it can be surely concluded that there are 21 data which have something to do with Gender Inequality and Equality and 43 data which have something to do with kinds of moral value. The analysis has two objectives. The first objective is to analyze the Gender Inequality which the movie brings and the second is to analyze the moral values which the movie wants to convey to the audience. Gender Inequality and Equality in the film "Wonder Woman" by Patty Jenkins. After analyzing the data found in film 
"Wonder Woman", the writer can draw conclusion that the Gender Inequality found in film "Wonder Woman". Gender Inequality is $33.45 \%$ and Gender Equality is $21,00 \%$. Based on the result of the data which exist on the film, Gender Inequality gets the highest percentage of the Gender Equality due the fact that film is about A woman who grew up believing in the need to fight is unusual. She wanted to fulfill her destiny as an Amazon to defend the world from the chaos and destruction of war. She is a fierce warrior and can't wait to show off her ability to defeat the enemy, but her goal in fighting is only to end the war itself. The Gender Equality gets lowest in percentage. It is not surprising since the equality in this film shown by Steve, not only Diana who learned valuable lessons, this film has two characters who study outside the 'comfort' of his world.

Moral value in film "Wonder Woman" by Patty Jenkins. After analyzing the data found in film "Wonder Woman" by Patty Jenkins, the writer can draw a conclusion that the moral value which emerge in film "Wonder Woman", Justice 17,41\%, Honesty 33,45\%, Bravery 17,10\%, Responsibility 30,89\% and Beneficence $31,11 \%$. Honesty and Beneficence get the highest percentage due the fact that the film would like to tell much about how to be honest and loving and caring for other. It's about being kind to others and not only thinking about yourself. This film also teaches the audience to never stop learning and to look beyond what can be seen. It is truly hopes that every person watching this film willing to apply it in their life in everyday living.

\section{References}

Bravo-Baumann, H. (2000). Gender and livestock. Swiss Agency for Development and Cooperation.

Chaplin, C., \& Robinson, D. (2012). My autobiography. Melville House. https://books.google.co.id/books?id=31UyYJnDhJsC

Clutterbuck, P. M. (2007). Value education: Book 2. Blake Education.

Creswell, J. W. (2009). Research Design: Qualitative, Quantitative and Mixed Approaches (3rd Edition). In Research Design: Qualitative, Quantitative, and Mixed Methods Approaches (3rd ed.). https://doi.org/10.2307/1523157

Endraswara, S. (2008). Metodologi Penelitian Sastra (2nd ed.). Pustaka Widyatama.

Hurlock, E. B. (1997). Psikologi Perkembangan Suatu Pendekatan Sepanjang Rentang Kehidupan (5th ed.). Erlangga.

Jayachandran, S. (2015). The roots of gender inequality in developing countries. Annual Review of Economics, 7(1), 63-88. https://doi.org/10.1146/annurev-economics-080614-115404

Jenkins, P. (2017). Wonder women. Warner Bros. https://www.imdb.com/title/tt0451279/

Pilcher, J., \& Whelehan, I. (2004). Fifty key concepts in gender studies. University of Manchester.

Sugiyono. (2009). Metode penelitian kualitatif. Alfabeta.

Thomas, P., \& Tylman, L. (2004). Gender and develompment directory. Australian Development Studies Network.

Tjahjadi, S. P. L. (1991). Hukum moral: Ajaran Immanuel Kant tentang etika dan imperatif kategoris. Kanisius. 